\title{
HOSPITAL STATISTICS AS A MEASURE OF EFFECTIVE MANAGEMENT OF HOSPITAL RESOURCES IN OBAFEMI AWOLOWO UNIVERSITY TEACHING HOSPITAL, ILE-IFE, OSUN STATE, NIGERIA
}

\author{
${ }^{1}$ Kayode Sunday Osundina and ${ }^{\mathbf{2}}$ Adebolu Faleye \\ Health Information Management Dept., Lead City University Ibadan \\ Corresponding Author's E-mail: kayodeosundina@yahoo.com
}

\begin{abstract}
This study examined the significance of hospital statistics in measuring effectiveness of hospital resources in Obafemi Awolowo University Teaching Hospitals Complex (OAUTHC), Ile-Ife, Osun State. The study made use of secondary sources of data where the basic hospital statistics such as daily admissions, discharges, deaths, patients' days, average census/ average daily bed occupied, patients' average length of stay, percentage of occupancy, turnover interval and daily attendance. The study showed that major hindrances for effective statistics in the hospital lack of understanding of the fundamental usefulness of statistics in planning, research, training and budgeting for national sustainable development. This study identified low level of understanding of the significance of statistics. Based on the findings of this study, the following recommendations are suggested for policy implementation: This study identified low level of understanding of the significance of statistics, hence, there is need for more awareness creation on the importance of statistics among members of the hospital that are involved in the completion and submission of the various forms where hospital statistics are generated through seminars, conferences and workshops Health information officers and other units such as the laboratories and the nursing departments need to be re-educated on the need for timely submission of statistics generated in the various units and sections. The hospital management needs to formulate policies that will support accurate and complete statistics from the various units that can be used for effective planning and informed decision making. The hospital management should endeavour to motivate the units and department that submit their reports promptly for collation in the form of training and other incentive that will encourage the same spirit among the concerned units and department respectively.
\end{abstract}




\section{INTRODUCTION}

The Nigerian Health service delivery is characterized by inequitable distribution of resources, decaying infrastructure, poor management of human resources for health, negative attitude of health care providers, weak referral systems; poor coverage with high impact costeffective interventions, lack of integration and poor supportive supervision. Besides, healthcare quality and safety require that the right information through accurate statistics be available at the right time to support patient care and health system management decisions. Gaining consensus on essential data content and documentation standards is a necessary prerequisite for high-quality data in the interconnected healthcare system of Nigeria. Continuous quality management of data standards and content is key to ensuring that information is usable and actionable (Alberta Occupational Profiles, 2011).

From time immemorial, Health Information Professionals are evaluated on the timeliness, completeness, and accuracy of the statistical reports they are responsible for preparing. It is therefore important to have policies and procedures that help ensure that reports meet these criteria. The collection of meaningful statistics is an important function of a hospital or clinic. Health records are the primary source of data used in compiling health care statistics. The health record department staff, therefore, may be responsible for the collection, analysis, interpretation and presentation of statistical data wherever possible.

Today, computerized systems automatically collect and calculate many of the statistics that were once previously done manually. However, statistics are only as accurate as the original sources from which they are taken. The health information management/health record professional should see that health records and other source documents are complete and readily available to meet the requirements for the production of useful statistics. From policy point of view, health service statistics are used for comparison of present and past performance of the hospital or clinic, guide for planning future development of the hospital or clinic, appraisal of work performed by the medical, nursing and other staff and hospital or clinic funding if government funded research. Research has shown that definitions used for the collection of statistical data on hospital utilization vary from country to country. However, the operational definition of terms has a comprehensive list of the terms used in hospital statistics and their meanings.

The concept of measurement is central to the concept of hospital quality improvement; measurement provides a means to define what hospitals actually do, and to compare that with the original targets in order to identify opportunities for improvement. The principal methods of measuring hospital performance are regulatory inspection, public satisfaction surveys, third-party assessment, and statistical indicators, most of which have never been tested rigorously.

The relevant environment for this study is the Obafemi Awolowo University Teaching Hospitals Complex, Ile Ife is one of the Federal Teaching Hospitals fully funded by the Federal Government of Nigeria. The hospital was formerly known as the Ife University Teaching Hospitals Complex until its name was changed in 1987 to Obafemi Awolowo University Teaching Hospital Complex in honour of one of the greatest statesmen Nigeria has produced, following the death of the sage in 1987. The Institution was the brain child of the government of the then Western State of Nigeria. In 1967, the Western State Government decided to establish a medical school in its University at Ile-Ife which was then five (5) years old to provide manpower to tackle the health problems of the state. After a period of careful planning, the Faculty of Health Sciences was created in the University of Ife on 8th May, 
1972. The teaching hospital that was to serve as a clinical facility to the medical school was established in July 1975. It was taken over by the Federal Government later that year.

The Obafemi Awolowo University Teaching Hospitals Complex is unique in character in that it was founded on what is generally referred to as the Ife Philosophy. The philosophy provides for an integrated health care delivery system with emphasis on comprehensive health care services based on a pyramid comprising primary care at the base, and secondary and tertiary services, designed to secure improvement in the physical, mental and socio-economic wellbeing of Nigerians through preventive, promotive, diagnostic, restorative and rehabilitative services. The philosophy allows for a unique experiment in health care delivery and health professional training in Nigeria. Primary Health Care is provided to the community in the health centers - two urban and one rural in its catchment areas of Ife, Ilesa and Imesi-Ile respectively. Secondary care is provided at its satellite centers and tertiary care for complicated disease conditions in specialized facilities in its two hospital units.

By its recognition and establishment of Primary Health Care as an integral part of the country's health system and the first level of contact of individuals, thereby bringing health care as close as possible to the people, the Obafemi Awolowo University Teaching Hospitals Complex was ahead of the WHO in its Alma Ata Declaration of 1978 that Primary Health Care is the key to attain health for all. The Ife philosophy has thus made for Obafemi Awolowo University Teaching Hospitals Complex a multi-campus health care system with six (6) units.

\section{STATEMENT OF THE PROBLEM}

The significance of hospital statistics in measuring effective hospital services in this contemporary society cannot be over emphasised. This is because statistics forms the bedrock of meaningful decision making and sustainable development at all levels of health care delivery system in Nigeria. However, evidences have shown that our policy makrs still base their decisions on mere guesswork rather than actionable data which is often generated through accurate statistics collation among Health Information Managers in the three tiers of health care in Nigeria. It is on this background that the current study is based with a view to contributing to existing literature on the role of statistics in effective management of hospital resources at the Obafemi Awolowo University Teaching Hospitals Complex, Ile-Ife.

\section{OBJECTIVES OF THE STUDY}

The general objective of the study is to investigate the role of hospital statistics in measuring effectiveness of hospital resources in Obafemi Awolowo University Teaching Hospitals complex (OAUTHC), Ile Ife, Osun State. This will be achieved by mean of the following specific objectives which are formulated to:

1. find out common health and vital statistics commonly generated in (OAUTHC), Ile Ife,

2. determine the scope of health and vital statistics generated in (OAUTHC), Ile Ife,

3. find out the common use(s) of daily, monthly, quarterly and annual statistics generated in the Department of Health Information Management in (OAUTHC), Ile Ife,

4. examine hindrances and challenges of effective statistical management in (OAUTHC), Ile Ife. 


\section{RESEARCH QUESTIONS}

The following research questions were answered

1. What are the common health and vital statistics generated in (OAUTHC), Ile Ife?

2. What is the scope of health and vital statistics generated in (OAUTHC), Ile Ife?

3. How are the daily, monthly, quarterly and annual statistics generated in the Department of Health Information Management in (OAUTHC), Ile Ife being utilized?

4. What hindrances and challenges of effective statistical management in (OAUTHC), Ile Ife?

\section{REVIEW OF LITERATURE}

\section{MEASURING HOSPITAL PERFORMANCE USING STATISTICS}

The hospital statistics is used as a tool for measuring the effectiveness of hospital services. The term "Measurement" implies objective assessment but does not itself include judgement of values or quality; these may be added by those who later present and interpret the data. At the system level, improvement in such areas as health priority setting, system planning, financing and resource allocation, professional recognition and overall quality management often become important aims of health reforms. At the national level, many countries, such as Ireland (Department of Health and Children's Services, 2001), Denmark (National Board of Health. National strategy for quality improvement in health care, 2002), the United Kingdom (http://www.doh.gov.uk/newnhs/quality.htm) and Germany (National recommendations on quality management in health care, 1998), have developed frameworks for performance assessment and improvement.

At the European level much work has been done to summarize data on hospital performance and quality assurance policies in the European Union ( Federal Ministry of Labour, Health and Social Affairs, 1998) ), accession states (Vienna, Federal Ministry, 2001) and other WHO Member States. General recommendations on the development and implementation of quality improvement systems in health care were made to health ministers by the Council of Europe in 1(997) and best practices in the efficient and effective delivery of services were published by the European Commission in (1999).

At the global level, findings concerning health systems performance measurement in 192 Member States were summarized in the WHO World Health Report (2000). This document sets out a framework for evaluating and improving performance of health systems in four key functions: providing services, creating resources, financing and oversight. Hospital performance may be defined according to the achievement of specified targets, either clinical or administrative (WHO, 1994). Ultimately, the goal of health care is better health, but there are many intermediate measures of both process and outcome. Targets may relate to traditional hospital functions, such as diagnosis, treatment, care and rehabilitation as well as to teaching and research. However, both the definition and the functions of hospitals are changing, as emphasis shifts from inpatient care to ambulatory care, community outreach programmes and health care networks (Healy \& McKee, 2002). Hospital performance may thus be expected to include elements of community care and public health, as well as social and employment functions. These dimensions of hospital performance have been analysed in the European context (Onyebuchi, 2003). 
Measurement is central to the concept of quality improvement; it provides a means to define what hospitals actually do, and to compare that with the original targets or expectations in order to identify opportunities for improvement. Hospitals have many targets and many stakeholders; these may be seen as clusters of values and aims behind performance measurement (Øvretveit, 2001), in such areas as:

- Research: Data about structure, activities and effectiveness can be used to study the link between organization and performance, and to inform planning and system development.

- Service improvement: Purchasers and providers can compare performance within and among hospitals to stimulate and measure change.

- Referrer and patient choice: Patients and their referrers can use information such as waiting times, outcomes and patient experiences in choosing a provider.

- Resource management: Purchasers and provider managers need data on performance, costs and volume of activity in order to decide on the best use of resources.

- Accountability: Politicians and the public increasingly demand transparency, protection and accountability for performance.

Hospitals need positive incentives to provide timely, accurate and complete data to external assessment programmes. If such programmes are perceived to have intrinsic value to the organization (for example, in staff motivation, team building; clinical and professional development or risk management), hospitals have less need for financial or market incentives to participate. Conversely, neither individuals nor hospitals are keen to provide information which might lead to public blame, litigation, and loss of staff, authority and trade. Many performance measurement systems assume a common culture of transparency, professionalism and accountability that motivates cooperation.

\section{METHODS OF MEASURING HOSPITAL PERFORMANCE USING STATISTICS}

The principal methods of measuring hospital performance are regulatory inspection, public satisfaction surveys, third-party assessment, and statistical indicators, most of which have never been tested rigorously. Evidence of their relative effectiveness comes mostly from descriptive studies rather than from controlled trials. The effectiveness of measurement strategies depends on many variables including their purpose, the national culture, how they are applied and how the results are used.

1. Inspection: Inspection of hospitals measures minimal requirements for the safety of patients and personnel; it does not foster innovation or information for consumers or providers. Most countries have statutory inspectorates to monitor compliance of hospitals with published licensing regulations. More specialized functions include fire, hygiene, radiation, medical devices and medicines, and some countries include infection control and blood transfusions. Inspections standards have legal authority and are transparent, but by the same token are not easily updated. Standards address the minimal legal requirements for a health care organization to operate and care for patients; they do not usually address clinical process or hospital performance. Licensing inspections often 
apply only to new hospitals, particularly in the private sector; where relicensing is applied, certificates may be issued on payment of a fee with minimal or no inspection. When assessment is managed locally by a governmental entity or its designated agent, there may be little national consistency or aggregation of reports, and when it is highly centralized, results are often not shared with staff or patients. Some governmental agencies for example, the Joint Commission in the United States - define the standards for hospital licenses, but issue them on the basis of assessments made independently by accreditation programmes that they monitor for conformity. In the United Kingdom, The Commission for Health Improvement (CHI) was designed to inspect arrangements for "clinical governance" in public hospitals in England and Wales. CHI published no standards for self-assessment and formed no reciprocation with independent or private organizations. Their reports are detailed and public. Inspection of hospitals induces conformity, and measures performance in terms of minimal requirements for safety. It does not foster innovation or information for consumers or providers.

2. Consumer surveys: Surveys usually address what is valued by patients and the general public. Standardized surveys measure specific domains of patient experience and satisfaction. There are also standardized surveys that reliably measure hospital performance against explicit standards at a national level.

Standardized surveys of patients and relatives can reliably measure hospital performance against explicit standards at a national level. Hospital performance is becoming more focused on health education, patient empowerment, comfort, complaint mechanisms and continuity of care. Some governments and intergovernmental organizations seek to make patients more aware of their rights - and to increase their sometimes very low expectations by publishing patients' charters and by legislating the protection of patients' rights. Thus, consumer surveys assessing the experience of health care and outcomes as perceived by patients and their families carry added weight. Some countries (including France and the United Kingdom) and most accreditation programmes require institutions to make systematic assessments of their patients' perceptions. Surveys range from local pencil-and-paper surveys outside a clinic to national stratified sample surveys.

National surveys are often managed under contract by independent organizations using validated tools to obtain reliable data; published results may identify the performance of individual hospitals. Advantages of this method are that it identifies what is valued by patients and the general public, and standardized surveys can be tailored to measure specific domains of experience and satisfaction. However, traditional satisfaction surveys have been methodologically weak, and focused on the agenda of clinicians and managers rather than patients. A review of 195 published studies suggested that few patient surveys were both valid and reliable (Sitzia, 1999), and governments may be reluctant to publish adverse results for public hospitals.

Many patients have low expectations and are too readily satisfied; systematic measurement of their experience is a more sensitive indicator of empowerment (Coulter, 2002). Researchers at Harvard Medical School developed and tested a standardized instrument to measure patients' concerns and experience. It was first used at a national level to interview hospital inpatients and relatives by telephone in the United States (Cleary, 1991), and has since been used as the so-called Picker Questionnaire in Australia, Canada (Charles, 1994) and various European countries (Bruster, et al, 1994; Gulacsi, 2001\& Coulter 2001). Favourable Picker scores have shown correlations to significantly reduced complications and 
unexpected deaths in Michigan hospitals (Bechel, et al, 2000), and low scores were associated with lower health status among patients with acute myocardial infarction in New Hampshire (Fremont , 2001).

In England, all hospitals are required to commission their own local surveys each year, including a standard set of questions for national performance monitoring and benchmarking. Results are submitted to the Department of Health for use in the National Performance AssessmentFramework. Aggregated results are published on the Internet (http://www.doh.gov.uk) and financial incentives are offered for demonstrably patientcentred care (Secretary of State for Health, 2000). Studies in, for example, France (Saloman, et al. 1999), Greece (Moumtzoglou, et al. 2000), Poland (Lawthers, et al, 1999), Sweden (Hansson et al, 19993) and the United Kingdom (Jenkinson, et al, 2002) have shown that inter-hospital comparisons are feasible at a local or regional level

3. Third party assessment: Third party assessments may include measurement by standards, by peer review or by accreditation programmes. ISO standards assess compliance with international standards for quality systems, rather than hospital functions per se. Peer review is generally supported by clinical professions as a means of selfregulation and improvement, and does not aim to measure the overall performance of hospitals. Accreditation programmes are managed by independent agencies in several countries. They focus on what may be improved rather than on failures, and are oriented toward the patient, the clinical procedures, outcome and organizational performance. These programmes require substantial investments, and there is ample evidence that hospitals rapidly increase compliance with published standards and improve organizational processes in the months prior to external assessment. There is less evidence that this brings benefits in terms of clinical process and patient outcome.

A research project funded by the European Union (Shaw, 2000) identified systematic approaches linking national or international standards to local practices of private or public hospitals. These approaches have been compared in a number of studies of standards and methods used by industry-based (ISO, Baldrige) and health-care-based (peer review, accreditation) programmes (Klazinga, 2000, Australian Business Excellence Framework Healthcare Advisory Group , 1999 \&Bohigas et al, 2000). The programmes, which are voluntary and independent to varying degrees, use explicit standards to combine internal selfassessment with external review by visits, surveys, assessments or audits (Shaw, 2001). As the previously cited survey of 195 studies (Sitzia , 1999) says: "Considering the amount of time and money spent on organizational assessment, and the significance of the issue to governments, it is surprising that there is no research into the cost-effectiveness of these schemes."

ISO Standards: International Organization for Standardization (http://www.iso.ch) certification measures hospital performance in terms of compliance with international standards for quality systems, rather than in terms of hospital functions and objectives. Details of assessments are not publicly available. ISO developed a series of standards (ISO 9000) originally for the manufacturing industries (medicines, medical devices) that have been used to assess quality systems in specific aspects of health services and hospitals and clinics. Hospitals (or, more commonly, parts of them) are assessed by independent auditors who are themselves regulated by a national "accreditation" agency. The theoretical advantage is that ISO certification is internationally recognized in many other services and manufacturing 
areas, but ISO 9000 standards relate more to administrative procedures rather than to hospital performance. Furthermore, the terminology of the standards is difficult to relate to health care, and interpretations vary among national agencies (Sweeney, 2000). The audit process tests compliance with standards and is not intended for organizational development. Few whole hospitals have been ISO certified and few countries have a national register of these hospitals.

The ISO 9000 standards for quality systems were adapted in 2000 to become more easily applied to health care and to include the assessment of outcomes and consumer satisfaction. There are initiatives in the United States (led by the major motor manufacturers who purchase health care for their employees) and in Europe (led by CEN) to interpret quality standards for health care. ISO15189 is becoming the international standard for medical laboratories and includes issues of clinical judgement, process and outcome.

Peer review: Peer review is a closed system for professional self-assessment and development. Reciprocal visiting is driven by professional (often single-discipline) organizations and has a long tradition as a form of peer review, especially for the recognition of training posts. It is endorsed by clinical professions as a means of self-regulation and clinical improvement, and is integrated with undergraduate, specialty and continuing professional development. Reciprocal visiting has also been applied to service development, such as in the hospital specialties programme in the Netherlands (Klazinga, 1998). Limitations of the method include its basis in specialties, as opposed to whole hospitals, and the confidentiality of its results. Peer review schemes could provide a source of standards and assessments to harmonize professional and human resource management within and between countries with reciprocal recognition of training.

Accreditation: Accreditation programmes measure hospital performance in terms of compliance with published standards of organizational - and, increasingly, clinical processes and results. They are mostly independent and aimed at organizational development more than regulation but could contribute reliable data to national performance measurement systems. They are independent, voluntary programmes developed from a focus on training into multi-disciplinary assessments of health care functions, organizations and networks. Their standards of assessment have been developed specifically for health care.

While the standards of accreditation are reliable, and the names of accredited hospitals are generally published on individual websites, many hospitals do not participate in voluntary programmes, and criteria and assessment processes vary from program to program. Details of survey results are not publicly available, except for governmental programmes. Measurements of hospitals include internal self-assessment, external survey by multi-disciplinary teams of health professionals, and benchmarking of a limited range of statistical indicators.

A global study identified 36 nation-wide accreditation programmes. A survey of the WHO European Region in 2002 (International Society for Quality in Healthcare, 2003) identified 17 such programmes focusing on whole hospitals. Mandatory programmes have recently been adopted in France (Décret en Conseild'Etat no. 97-311 du 7 Avril, 1997), Italy (Decree of 14 January 1997) and Scotland (Steele, 2000). 
National programmes within Europe have agreed in principal to voluntary convergence of standards and assessment processes according to the ALPHA Principles of the International Society for Quality in Health Care (ALPHA program, 2000). The ALPHA programme aims to make standards-based assessment systems more reliable, valid and compatible within and between countries (Heidemann, 2000). Most established programmes have been subjected to internal (Clinical Standards Board for Scotland. Developing the review process; Shaw, 1995 or external evaluation (Bukonda et al., 2000; Duckett \& Coombs, 1982; Scrivens, 1995 \& Williamson, et al. 1998), but few of these evaluations have used comparable methods to permit synthesis.

The potential for provider profiling from accreditation surveys greatly exceeds what is available from routine statutory returns and minimum data sets, but most accreditation programs do not fully utilize this capacity. Inhibiting factors include the ownership by institutional customers of the raw data, and the costs of developing and maintaining an analytical database without a guaranteed market for its products.

Statistical indicators: Statistical indicators can suggest issues for performance management, quality improvement and further scrutiny; however, they need to be interpreted with caution. Much of the current evidence on the effectiveness of performance indicators is based on observational or experimental data. Some experience suggests that indicators such as guidelines to standardize management of common conditions may reduce length of stay and episode costs without detriment to clinical outcome. The publication of performance statistics as "league tables" aims to encourage improvement, to empower patient choice and to demonstrate a commitment to transparency. Evidence suggests that this increases public interest and management attention to data quality, but it does not appear to have much effect on performance.

Statistical indicators can suggest issues for performance management, quality improvement and further scrutiny. They provide relative rather than absolute messages and need to be interpreted with caution inversely proportional to the quality of the underlying data and of the definitions used. Indicators are tools for assessing hospital performance either internally or externally. They should be designed to measure the achievement of predetermined objectives, but in practice they are often selected on the basis of whatever data are routinely available. Standardization is essential for measurements within hospitals, and critical for measurements between hospitals.

Performance measurements from individual hospitals may be submitted as calculated indicators or as raw data to be processed, aggregated, analysed and presented by a central agency. Results are usually disseminated through government publication, website or independent media aimed at consumers, together with guidance on interpretation. Statistical indicators represent an accessible, fairly economical, potentially standard and non-invasive means of performance measurement, but there are many cautions associated with their use: Interpretation of "raw" data on hospital performance, even after adjustment for case-mix and severity, is dependent on many social or economic variables beyond the hospital's control. Moreover, hospitals might modify internal data collection in order to "meet" external targets, or deny interventions to high-risk individuals in order to improve outcomes. A 1995 study in the United Kingdom found that acute myocardial infarction outcome data did not show "gross failures of care" (McKee \& Healy, 2002). A 1996 study in the United States showed that outcome data did not identify poor quality hospitals (McKee \& Healy, 2002). 
- Research in the USA and Europe has shown wide variations in values expressed by patients, and in their use of information designed to empower them $(60)$.

- Published results should highlight broad differences rather than precise rankings

\subsection{INTEGRATING PERFORMANCE MEASUREMENT SYSTEMS IN THE HOSPITALS}

Recent national reports from Australia (Report of the National Expert Advisory Group on Safety and Quality in Australian Health Care. 1998), Scotland (Scottish Office , 1998) and the United States (President's Advisory Commission on Consumer Protection and Quality in the Health Care Industry, 1998) have examined how external mechanisms for performance measurement contribute to internal development and public accountability. The common conclusions from these countries are that:

- Voluntary and statutory agencies should be actively coordinated for consistency and reciprocity.

- Consumers should be prominently involved.

- National programmes should be comparable internationally.

- The standards, processes and results of external assessments should be transparent and freely accessible to the public.

\subsection{PUBLIC DISCLOSURE OF HOSPITAL PERFORMANCE DATA}

The publication of hospital activity and results as "league tables" aims to encourage improvement, to empower patient choice and to demonstrate a commitment to transparency. Evidence suggests that this increases public interest and management attention to data quality but it does not appear to have much effect on performance:

- Most publication schemes have been found to have little effect on patient choice behaviour, provider behaviour or outcome performance.

- The United States Health Care Financing Administration published hospital mortality rates in 1988, publication was stopped 1995 because of criticism of the data's validity and the view that publication did not stimulate improvement but caused defensiveness and fear among providers. A 1995 survey of Pennsylvania cardiologists found the consumer guide to coronary artery bypass graft surgery to be "of little or no influence" in choice of surgeon and not much used by consumers ( Schneider \& Epstein, 1996).

- One study argues that on statistical grounds, "the current official support for output league tables, even adjusted, is misplaced" (Goldstein \& Spiegelhalter, 1996).

\subsection{STATISTICAL REPORTING}

Quite frequently, the health facility's administrator, accreditation agency, or a government agency establishes various reports that must be presented. It is important to ensure that these reports are prepared in a timely and accurate manner since, directly or indirectly, this is one of the ways the health record department is evaluated.

The data collected and reports prepared should be reviewed and evaluated on at least an annual basis to determine if they are be used. Data that are collected for no apparent reason or reports that are prepared that no one uses are a waste of staff time and resources. Sometimes 
reports prepared only present the work accomplished during the reporting period, and may not be particularly useful for problem identification or for decision-making. A report that compares selected data and indicators over different time periods may prove useful. For example, the data and indicators for a month and the year to date can be compared with data for the same month and year to date of the previous year

\subsection{OVERVIEW OF HOSPITAL STATISTICAL DATA COLLECTION AND CALCULATIONS}

The International Federation of Health Information Management Associations (2012) identified some standardized inpatients and outpatients' statistical data collection and calculations as presented below:

\subsubsection{THE INPATIENT STATISTICAL DATA COLLECTION AND CALCULATIONS}

Inpatient statistical data routinely collected and calculated in hospitals on a monthly and annual basis include:

1. number of admissions - total hospital and by service

2. number of patient days

3. number of discharges (live and expired) - total hospital and by service

4. number of deaths - total hospital and by service

5. total length of stay (total discharge days)

6. number of autopsies

7. number of Coroner's (medical examiner's) cases

8. number of deliveries (obstetric patients)

9. number of live births

10. number of fetal deaths

11. number of obstetric discharges

12. number of maternal deaths

13. number of prenatal deaths

14. number of surgical procedures

15. number of anaesthetics administered

The above information is used to calculate the following rates and percentages:

\section{(a) Hospital utilization}

daily census $\square$ average daily census $\square$ average length of stay of inpatients percentage of occupancy of hospital beds $\square$ turnover interval $\square$ turnover rate

(b) Death rate

$\square$ hospital death rate $\square$ net death rate $\square$ postoperative death rate $\square$ anesthesia death rate

(c) Autopsy rates

$\square$ hospital autopsy rate $\square$ net autopsy rate

(d) Obstetric and prenatal rates

$\square$ caesarean section rate $\square$ maternal death rate $\square$ fetal death rate $\square$ prenatal death rate The above rates and percentages may be calculated using the following formulae:

\section{Hospital Utilization}

\section{Daily Census (Daily Bed Occupancy)}

\section{Formula:}


Census = Inpatients Admissions up Discharges/deaths remaining at to the next between census midnight the + census hour - taking hours previous night

2. Average Daily Census (Average Daily Bed Occupancy): The average number of inpatients present each day for a given time period. This figure is derived by dividing the sum of patient days for a period by the number of days in the same period.

Formula:

\section{Total number of patient days for a period (except newborn)}

Total number of days in the same period

Example: In May a hospital rendered 4,280 patient days (excluding newborn babies). May has 31 days. Using the above formula the average daily census is calculated as follows:

$\underline{4280}$

$31=138.06$ or 138.1 . This would be rounded to give the average daily inpatient census during May of 138 patients. NOTE: This indicator is calculated separately for newborns.

3. Average length of stay (ALOS) of discharged patients: The average number of days that inpatients (exclusive of newborn) remained in the hospital.

Formula

\section{Total length of stay of discharged patients for a given period}

Total number of discharges and deaths in the same period

Example: In June a hospital discharged 2,086 patients (including deaths, but excluding newborns). Their combined length of stay was 13,654 days. Using the above formula the average length of stay of these patients was:

$\underline{13654}$

$2086=\quad 6.54$ or 6.5 days

4. Percentage of occupancy of inpatient beds: The percentage of inpatient beds occupied over a given period.

Formula

Total number of patient days for a given period $x 100$

Available beds (bed complement) $x$ the number of days in the period

Example: A hospital with 210 available beds (excluding newborn bassinets) rendered 4,780 patient days in June. June has 30 days. The percentage of occupancy for the hospital in June was:

$\underline{4780 \times 100}=\underline{78000}=$

$210 \times 30630075.87$ or $75.9 \%$

5. Bed Turnover Interval: Average period in days that an available bed remains empty between the discharge of one inpatient and the admission of the next. Indicates the time 
that available beds are free. Indicates a shortage of beds when negative, and under-use of the hospital or an inefficient admission system, if positive.

\section{Formula}

Available beds $x$ days in the period-patient days for the period

Number of discharges, including deaths, in the period

Example: A hospital with 210 available beds in June rendered 4,780 patient days and had 736 discharged/died patients. The turnover interval rate using the above formula is:

$\underline{210 \times 30-4780}=\underline{1520}$

$736 \quad \frac{1520}{736}=2.06$ or 2.1 days

6. Bed Turnover Rate: The mean number of patients "passing through" each bed during a period. Indicates the use made of available beds.

\section{Formula}

\section{Number of discharges (separations) in the period}

Example: During the month of June there were 736 discharges (including deaths) from a hospital with 210 beds. The turnover rate for June was:

$\underline{736}=$

2103.50 or 3.5

\section{Death Rates}

Note: Patients who are dead on arrival (DOA) at a hospital are not included when calculating these rates.

8. Hospital Death Rate: A ratio of all inpatient deaths for a given period to the total number of discharges and deaths in the same period.

\section{Formula}

\section{Total number of deaths of inpatients in a given period $x 100$}

Total number of discharges and deaths in the same period

Example: A hospital had a total of 15 deaths during the month of June. A total of 540 patients were discharged (including the 15 deaths) during the month. The hospital death rate according to the above formula is:

$\underline{15 \times 100}$

$$
540=\quad 2.77 \text { or } 2.8 \%
$$

9. Net Death Rate: A death rate, also known as the institutional death rate that does not include deaths, which occur within 48 hours of admission (24 hours of admission in some countries). Previously, it was that those deaths that occur within 48 hours of admission should not be counted because not enough time had lapsed to allow the health care providers adequate time to directly affect the patient's condition. However, with today's technology, this concept is no longer thought to be valid. Therefore, it is recommended that net 


\section{Formula}

Deaths minus those w/in 48 hours of admission in a given period $x 100$

Total number of discharges and deaths, minus Deaths w/in 48 hours of admission w/in the same period

Example: Taking the above example, of the 15 deaths, 4 patients died under 48 hours, leaving 11 patients who died 24 hours or more after admission. The total discharges, including deaths were 540. According to the formula the deaths under 48 hours of admission are deducted. Therefore, the calculation of the net death rate would be as follows:

$\underline{15-4 \times 100}=\underline{11 \times 100}$

$540-4536=2.09 \%$ or $2.1 \%$

10. Postoperative Death Rate: The ratio of deaths within 10 days after surgery to the total number of patients operated on during that period. Some healthcare providers question the usefulness of this rate, as it is questioned how ten days is considered the "magic number."

Formula

Total number of deaths (within 10 days of surgery) $X 100$

Total number of patients who were operated on for the period

Example: During the month of November a hospital performed 275 operations, and 269 patients were operated on. There were 2 deaths that occurred within 10 days of surgery, and 1 that occurred after 10 days. The postoperative death rate according to the above formula is:

$\underline{2 \times 100}=0.74 \%$

269

Note: it is recommended with small percentages of this nature, that the percentage be left at two decimal places.

11. Anesthesia Death Rate: The ratio of deaths caused by anesthetic agents during a administered. This formula includes those deaths that occurred within 10 days of surgery.

Formula

\section{Total deaths caused by anesthetic agents X 100}

Total number of anesthetics administered

Example: During the month of August a hospital performed 750 operations, and 750 anesthetics were administered. There was 1 death due to anesthesia. The anesthesia death rate according to the above formula is:

$\underline{1 \mathrm{X} 100}=0.13 \%$

750 


\section{Autopsy Rates}

- Hospital autopsy rate: The ratio of all autopsies performed in the hospital to all inpatient deaths in the hospital. Patients who are dead on arrival (DOA) at the hospital and fetal deaths are excluded from both the numerator and the denominator

\section{Formula}

\section{Total number of autopsies for a given period $x 100$}

Total number of inpatient deaths for the same period

Example: In a hospital with 15 deaths during the month of June, 7 autopsies were performed on hospital patients whose bodies were available for hospital autopsy. The hospital autopsy rate is calculated as follows:

$\underline{7 \times 100}$

$15=46.66$ or $46.7 \%$

- Net autopsy rate: A hospital may be prevented from performing an autopsy because the death is a coroner's or medical examiner's case and must be sent to the coroner's court for autopsy. It would not reflect the scientific interest of the doctors to include such cases in a measure of unautopsied hospital cases. Cases, which are not available for autopsy, are not included in the net autopsy rate.

Formula

Total number of autopsies for a given period $x 100$

Total number of deaths minus unautopsied Coroner's cases for the same period

Example: In the above example, of the 15 deaths and 7 autopsies in June 2 deaths were reported to the coroner/medical examiner and the bodies removed from the hospital and no hospital autopsy was performed. The net autopsy rate, therefore, was:

$\underline{7 \times 100}=\underline{700}$

$15-213=53.84$ or $53.8 \%$

\section{Obstetric and Prenatal Rates}

- Cesarean section rate: A ratio of the number of cesarean sections performed to total deliveries.

\section{Formula}

Total number of cesarean sections performed in a period $x 100$

Total number of deliveries in the period

Example: During the month of May, 310 deliveries occurred. Of this number 5 deliveries were by cesarean section. Using the above formula, the cesarean section rate is calculated as follows:

$\underline{5 \times 100}$

$310=1.61$ or $1.6 \%$ 
Maternal Death Rate: The ratio of maternal deaths to total obstetric discharges, including deaths. NOTE: Deaths due to abortions are maternal deaths even though the patient may have been hospitalised on a gynaecology ward.

\section{Formula}

\section{Total number of maternal deaths for a given period $x 100$}

Total number of obstetric discharges, including deaths, for the same period

Example: During May an obstetric hospital discharged 230 obstetric patients, of this number, 1 patient died. Using the above formula the maternal death rate would be:

$\underline{1 \times 100}$

2300.43 or $0.4 \%$

231

Prenatal Death Rate: The ratio of prenatal deaths to live births and fetal deaths.

\section{Formula}

Total number of prenatal deaths in a given period $x 100$

Total number of live births and fetal deaths in the same period

Example: In the month of May, there were 294 births, including 4 fetal deaths, and 2 babies subsequently died within seven days of birth. The perinatal death rate for May, therefore, was:

$\underline{6 \times 100}$

$294=2.04$ or $2.0 \%$

13. Fetal Death Rate: A ratio of fetal deaths to the total number of live births and fetal deaths in a period.

\section{Formula:}

Total number of fetal deaths for a given period $x 100$

Total number of births and fetal deaths for the same period

Example: The fetal death rate, using the prenatal death rate example above, is calculated as follows:

$\underline{4 \times 100}$

$294=1.36$ or $1.4 \%$

\section{THE OUTPATIENT STATISTICAL DATA COLLECTION AND CALCULATION}

The various outpatient statistical data collection and calculations include:

1. number of outpatient visits

2. number of outpatient visits for each clinic

3. number of emergency department visits 
4. occasions of service (i.e., number of special services, e.g. Ultrasound, X-ray, pathology tests)

Most of the above are collected to assess the workload of each department or clinic, and plan for future needs. It may be found that the Wound Clinic staff see twice as many patients than other clinics, therefore more staff will be required in the clinic area on the wound clinic days; or, patient waiting time may be too long and the administration decides to look at the statistics for each clinic to see if it is because too many patients are given appointments when sufficient medical staff are not available. This data may be manually tallied each day and totalled at the end of the time frame, or if a computerized patient registration system is used, the computer may automatically count these statistics. Therefore, no formulae are necessary to calculate this information.

1. Outpatient Visits (per day or per clinic session): The average number of patients seen per day or per clinic session.

\section{Formula}

Total number of visits in period

Total number of days in the time period (or clinic session held)

Example: During the month of September the Wound Clinic was held 12 times and there were 287 visits. Using the above formula, calculate the number of visits per clinic session.

$\frac{287}{12}=23.92$ or 23.9

\section{METHODOLOGY}

The researches design adopted for this study is explorative study. It involves data collection through secondary sources. The study population comprises all health statistics generated and collated between 2010 and 2014 at the statistics section of Health Information Management Department, OAUTHC, Ile-Ife, Osun State.

Purposive sampling technique was used for data collection. The sample size involves all Patients who attended their clinics the hospital in the last 5 years (2010-2014).

The researcher will made use of secondary data. Hence, the instrument was based on the structure and nature of statistical data available in the statistics section of the Health Information Management Department, OAUTHC, Ile-Ife.

\section{DATA ANALYSIS AND INTERPRETATION}

The chapter is presented in two main parts namely: (1) the presentation of the major health statistics generated in the hospital, and (2) the analysis of research questions and or objectives. 
DATA ANALYSIS INTERPRETATION TABLE 4.1

Table 1 showing the summary of hospital statistics generated between 2010-2014

\begin{tabular}{|c|c|c|c|c|c|c|c|c|c|}
\hline $\begin{array}{l}\text { Reference } \\
\text { Years }\end{array}$ & $\begin{array}{l}\text { Total Daily } \\
\text { Attendance }\end{array}$ & $\begin{array}{c}\text { Total } \\
\text { Admissi } \\
\text { on }\end{array}$ & $\begin{array}{c}\text { Total } \\
\text { Discha } \\
\text { rge }\end{array}$ & $\begin{array}{c}\text { Total } \\
\text { Death } \\
\text { s }\end{array}$ & $\begin{array}{c}\text { Tota } \\
\text { Patients } \\
\text { Days }\end{array}$ & $\begin{array}{c}\text { Average } \\
\text { Daily Bed } \\
\text { Occupied }\end{array}$ & $\begin{array}{l}\text { Average } \\
\text { Length } \\
\text { Of Stay }\end{array}$ & $\begin{array}{c}\text { Percen } \\
\text { tage of } \\
\text { Occup } \\
\text { ancy }\end{array}$ & $\begin{array}{r}\text { Turnover } \\
\text { Interval }\end{array}$ \\
\hline 2010 & 108,468 & 6,253 & 5,519 & 494 & 61,879 & 177 & 10 & 49 & 11 \\
\hline 2011 & 114,986 & 7,502 & 6,551 & 593 & 79,205 & 217 & 11 & 60 & 8 \\
\hline 2012 & 137,008 & $\mathbf{8 , 1 7 7}$ & 7,134 & 629 & 77,328 & 216 & 10 & 53 & 9 \\
\hline 2013 & 123,500 & 6,316 & 5,698 & 458 & 71,242 & 195 & 12 & 38 & 19 \\
\hline 2014 & 92,257 & 5,332 & 4,836 & 425 & 57,512 & 182 & 11 & 35 & 21 \\
\hline
\end{tabular}

From the summary in table 4.1 below, it is obvious that year 2012 seems to experience more patients inflow and outflow in the hospital than other years except in year 2011 when total patient days $(79,205)$ was more than that of year 2012 , that is $(77,328)$ implying that more people including those on admission were recorded in year 2012. It implies that since 2012, the hospital has experienced quite a low patient's attendance. Also, figures 1-9 shows the presentation of the various health and vital statistics generated in (OAUTHC) between the years under study. 


\subsection{ANALYSIS OF RESEARCH OBJECTIVES/RESEARCH QUESTIONS}

Research Questions $1 \&$ 2: What are the common and scope of health and vital statistics generated in OAUTHC Ile Ife?

\section{Figure 1: Five year analysis of total daily attendance in OAUTHC, Ile-Ife}

\footnotetext{
$160,000.00$

$140,000.00$

$120,000.00$

$100,000.00$

$80,000.00$

$60,000.00$

$40,000.00$

$20,000.00$
}

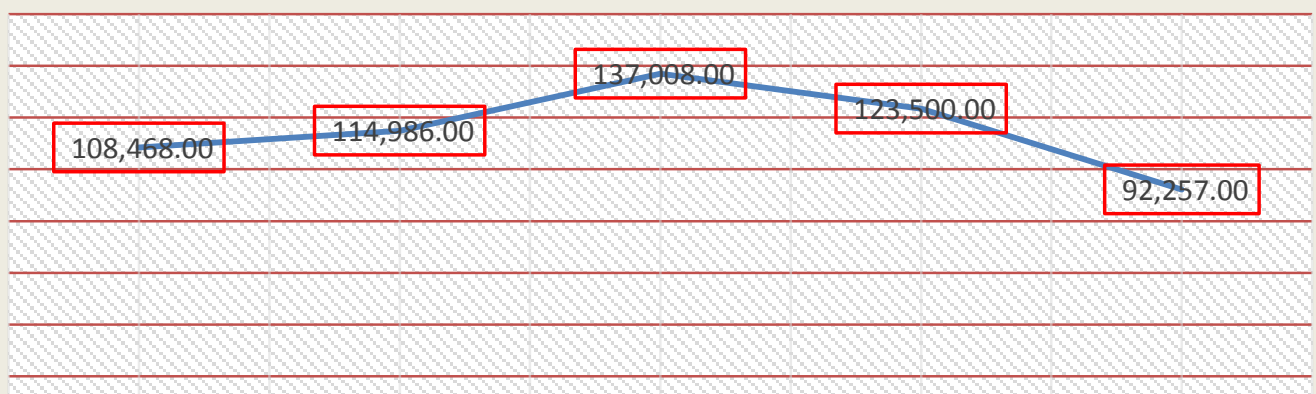

2010

2011

2012

2013

2014

Figure 2: Five year analysis of total admissions in OAUTHC, Ile-Ife

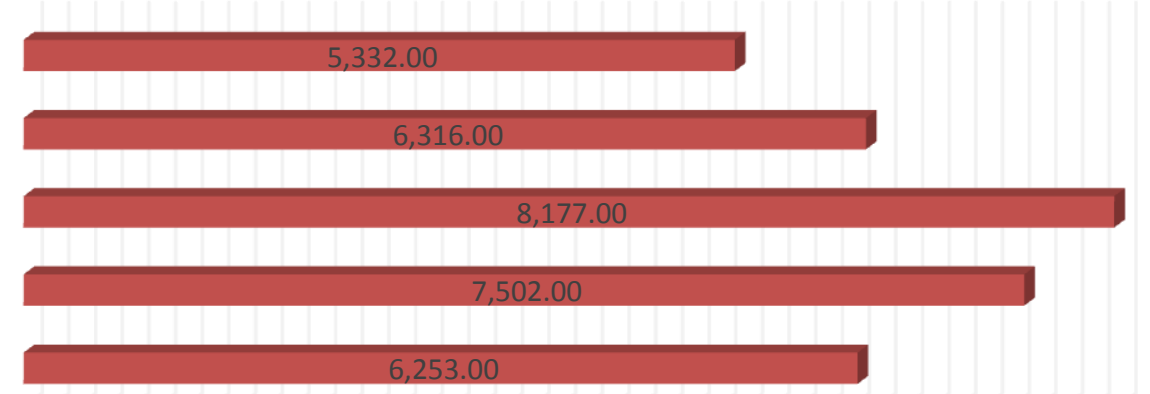

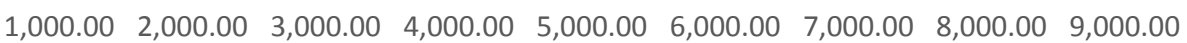




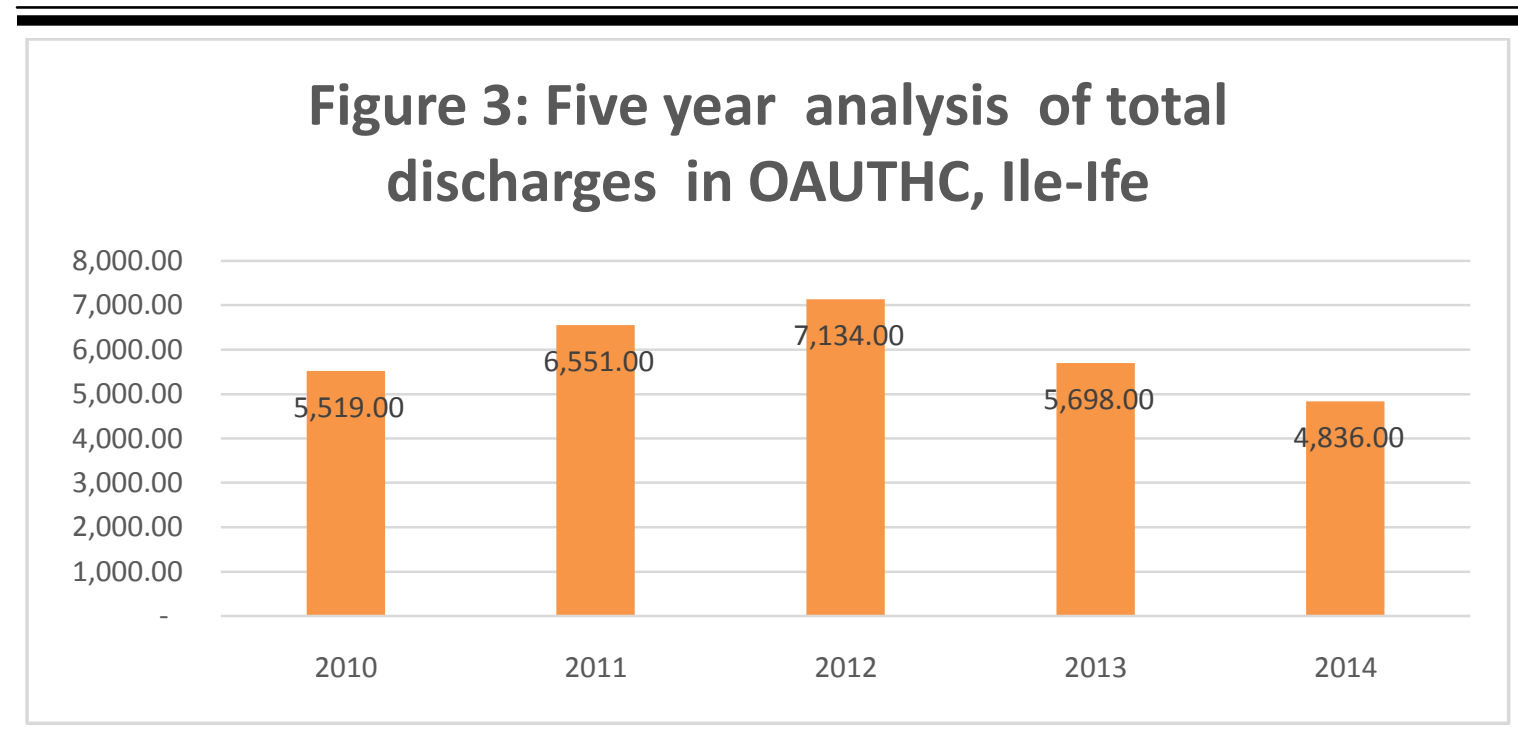

\section{Figure 4: Five year analysis of total deaths in OAUTHC, Ile-ife}

700.00

600.00

500.00

400.00

300.00

200.00

100.00

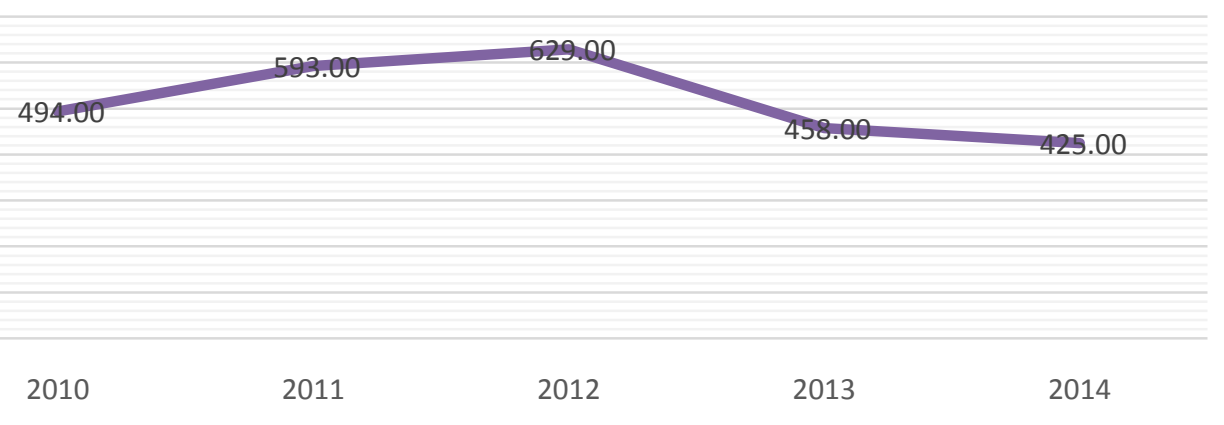




\section{Figure 5: Five year analysis of Total Patients Days}

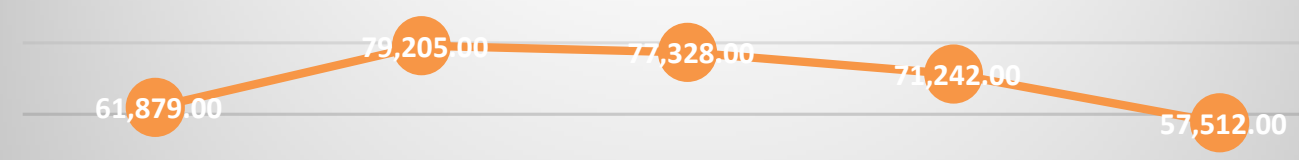

\section{Figure 6: Five year analysis of average daily Bed occupied}

\subsection{0 \\ 200.00 \\ 150.00 \\ 100.00 \\ 50.00}
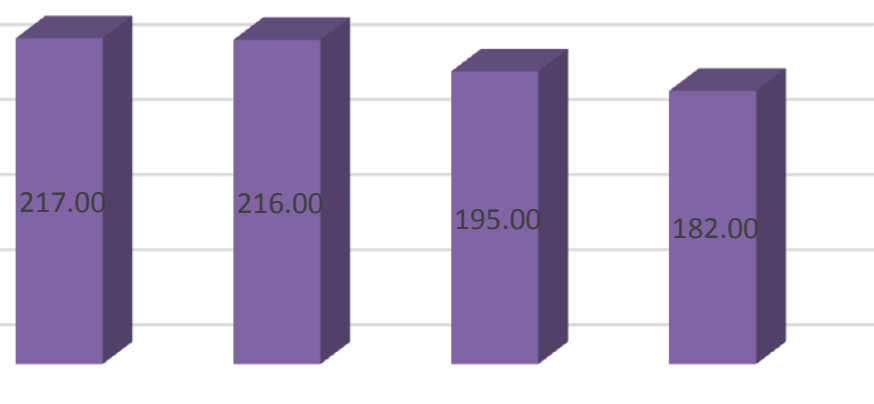

2010

2011

2012

2013

2014 


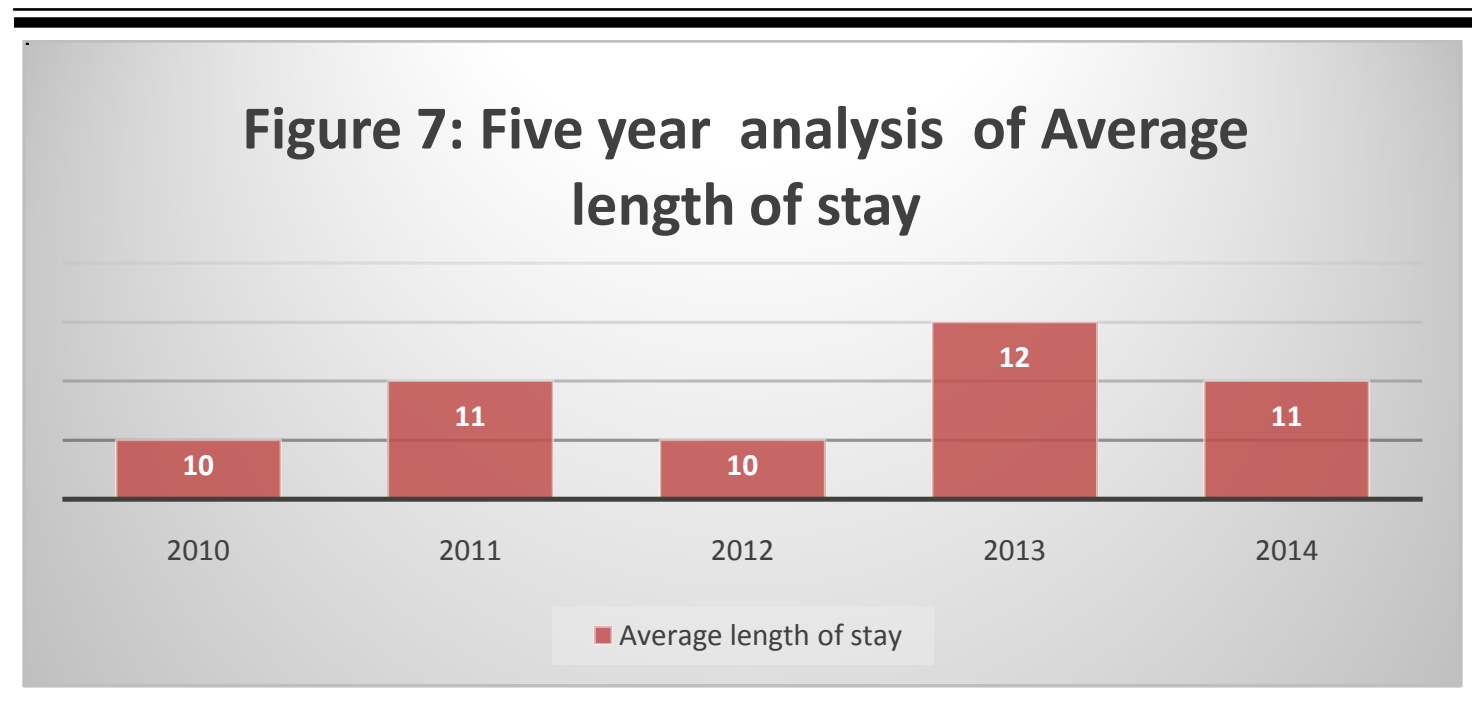

Figure 8: Five year analysis of percentage of bed occupancy in OAUTHC

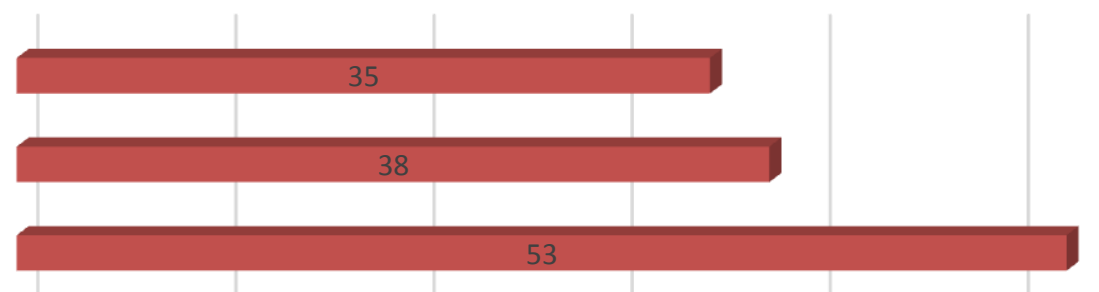

10

20

30

40

50

60 


\section{Figure 9: Five year analysis of turnover interval in OAUTHC, Ile-Ife}

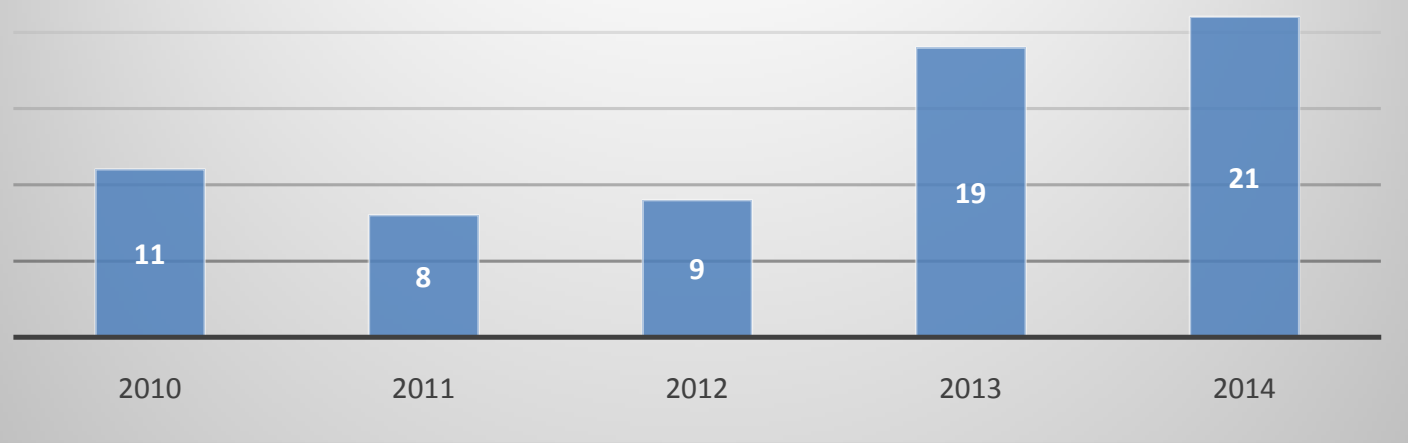

From the analysis in figures 1-9 above, it is obvious that the health statistics generated in (OAUTHC) includes daily admissions, discharges, deaths, patients' days, average census/ average daily bed occupied, patients' average length of stay, percentage of occupancy, turnover interval and daily attendance. Each of these statistics is significant in the formulation and implementation of health policy at the tree levels of health care in Nigeria.

There was a monthly record of movement of these figures to the federal statistics offices including the ministry of health. Beyond those presented in the table and figures, there are other statistics such as juvenile and children's statistics that also serve as impute into health planning for sustainable national development.

Research Questions 3: How are the daily, monthly, quarterly and annual statistics generated in the Department of health information management in OAUTHC, Ile-Ife being utilized?

Common use(s) of daily, monthly, quarterly and annual statistics generated in the Department of Health Information Management in (OAUTHC), Ile Ife,

The analysis showed that the data generated from the hospital statistics is used for the following:

1. For procurement of medical equipment for effective health care delivery to the general public in the areas of the hospital's mandates.

2. Used for application for medical grants for the different statistics for research and planning.

3. Statistics helps government and the hospital management to identify areas within the hospital that require recruitment of more staff.

4. For research and other scientific investigations.

5. Statistics helps to notify the government maternal mortality.

6. It helps to notify the government about a disease outbreak in a particular environment such as Ebola and laser fever. 


\section{Research Questions 4:}

What hindrances and challenges of effective statistical management in (OAUTHC), Ile Ife?

The study identified the following hindrances for effective statistics in OAUTHC, Ile-Ife:

1. Lack of cooperation between health information officers and the nurses in the different wards and clinics on the collection and submission of the statistics generated in the various units to the statistics section of the hospital.

2. Poor interprofessional collaboration between the laboratory scientists and health information officers on the submission of statistics generated at the hospitals' laboratories.

3. Late submission of statistics among health information officers in the various outpatients departments.

4. General poor understanding of the importance of statistics among the workers including health information management staff.

5. Lack of cooperation between the theatre staff and health information officers in the completion and submission of statistics generated in the theater.

\section{V.Summary}

This study examined the significance of hospital statistics in measuring effectiveness of hospital resources in Obafemi Awolowo University Teaching Hospitals Complex (OAUTHC), Ile-Ife, Osun State. The study made use of secondary sources of data where the basic hospital statistics such as daily admissions, discharges, deaths, patients' days, average census/ average daily bed occupied, patients' average length of stay, percentage of occupancy, turnover interval and daily attendance. The study showed that major hindrances for effective statistics in the hospital were lack of understanding of the fundamental usefulness of statistics in planning, research, training and budgeting for national sustainable development.

\section{CONCLUSION}

This study concluded that statistics remain the bedrock for an informed decision making among policy makers in the health sector. The study also concluded that the major ingredient of effective statistical collation is the collective efforts of all concerned units and department within the hospital such as nursing, laboratories and the medical and surgical departments.

\section{RECOMMENDATIONS}

Based on the findings of this study, the following recommendations are suggested for policy implementation:

1. This study identified low level of understanding of the significance of statistics, hence, there is need for more awareness creation on the importance of statistics among members 
of the hospital that are involved in the completion and submission of the various forms where hospital statistics are generated through seminars, conferences and workshops

2. Health information officers and other units such as the laboratories and the nursing departments need to be re-educated on the need for timely submission of statistics generated in the various units and sections

3. The hospital management needs to formulate policies that will support accurate and complete statistics from the various units that can be used for effective planning and informed decision making

4. The hospital management should endeavour to motivate the units and department that submit their reports promptly for collation in the form of training and other incentive that will encourage the same spirit among the concerned units and department respectively. 


\section{REFERENCES}

Australian Business Excellence Framework Healthcare Advisory Group. A comparison of quality programmes. Australian Quality Council, 1999.

Bechel DL, Myers WA, Smith DG. Does patient-centered care pay off? Joint Commission journal on quality improvement 2000, 26:400-409.

Bohigas L, Heaton C. Methods for external evaluation of health care institutions. International journal for quality in health care, 2000, 3:231-238.

Bruster S et al. National survey of hospital patients.BMJ 1994, 309:1542-1546.

Bukonda N et al. Setting up a national hospital accreditation program: the Zambian

experience. Bethesda: Quality Assurance Project, 2000.

Charles C et al. How was your hospital stay? Patients' reports about their care in Canadian hospitals. Journal of the Canadian Medical Association 1994, 150: 1813-1822.

Cleary PD et al. Patients evaluate their hospital care: a national survey. Health Affairs 1991, 10:254-267.

Coulter A, Cleary PD. Patients' experience with health care in five countries. Health affairs 2001, 20:244-252.

Coulter A.The autonomous patient: ending paternalism in medical care. London, Nuffield Trust, 2002.

Council of Europe, Recommendation No.R(97) 17 of the Committee of Ministers to member States on the development and implementation of quality improvement systems in health care. Strasbourg, 1997, (http://www.cm.coe.int/ta/rec/1997/97r17.html).

Davis, Nadinia, and LaCour, Melissa.Introduction to Health Information Technology. Philadelphia, PA: W.B. Saunders, 2002.

Decree of 14 January 1997. Rome, GazettaUfficialedellaRepubblicaItaliana, February, 1997.

Décret en Conseild'Etat no. 97-311 du 7 Avril. Paris, Journal Officiel (82)-8, 1997, (http://www.anaes.fr/ANAES/anaesparametrage.nsf/).

Department of Health and Children's Services. New Health Strategy.Dublin, November 2001, (http://www.doh.ie/hstrat).

Directorate-General for Employment, Industrial Relations. Best practice: state of the art and perspectives in the EU for improving the effectiveness and efficiency of European health systems. Luxembourg: Office for Official Publications, 1999.

Donahue KT, van Ostenberg P. Joint Commission international accreditation: relationship to four models of evaluation. International journal for quality in health care, 12:243-246. 
Duckett SJ, Coombs EM. The impact of an evaluation of hospital accreditation. Health Policy Quarterly, 1982, 2(3-4):199-208.

European Clearing Houses on Health Care Outcomes (http://www.leeds.ac.uk/nuffield/infoservices/ECHHO/home.html).

Federal Ministry of Labour, Health and Social Affairs. Quality in health care: opportunities and limits of cooperation at EU-level. Vienna, 1998, (http:// www.bmags.gv.at).

Federal Ministry of Social Security and Generations. Quality policy in the health care systems of the EU accession candidates. Vienna, Federal Ministry, 2001, (http://www.gesundheit.bmsg.gv.at).

Fremont AM et al. Patient-centered processes of care and long-term outcomes of myocardial infarction. Journal of general internal medicine, 2001, 16:800-808.

Goldstein H, Spiegelhalter DJ. League tables and their limitations: statistical issues in comparisons of institutional performance. Journal of the Royal Statistical Society, 1996, 159:385-443.

Guisset, A-L, Sicotte C, Champagne F. Background information on evaluation systems. Second Workshop on Hospital Performance Measurement Barcelona, Spain, 21-22 March 2003. World Health Organization.

Gulacsi L. Quality of health care: patient satisfaction and patient reports in Hungarian hospitals. In: Gulacsi L (ed.) Hungarian health care in transition. University of Amsterdam Press, 2001.

Hansson L, Bjorkman T, Berglund I. What is important in psychiatric inpatient care? Quality of care from the patient's perspective. Quality Assurance in Healthcare, 1993, 5:41-47.

Healy J, McKee M. The role and function of hospitals. In: McKee M, Healy J, eds. Hospitals in a Changing Europe. Buckingham, Open University Press, 2002.

Heidemann EG. Moving to global standards for accreditation processes: the ExPeRT project in a larger context. International journal for quality in health care, 2000, 12:227-230.

Horton, Loretta A. Calculating and Reporting Healthcare Statistics. Chicago, IL: AHIMA, 2004.

Huffman, Edna K. Health Information Management. 10th ed. Berwyn, IL: Physicians Record Company, 1994.

International Organization for Standardization, (http://www.iso.ch).

International Society for Quality in Healthcare. Global review of initiatives to improve quality in health care. Geneva, World Health Organization, 2003.

Jenkinson $\mathrm{C}$ et al. The coronary heart disease in-patient experience questionnaire (I-PEQ (CHD)): results from the survey of National Health Service patients. Quality of life research, 2002,11(8):721-727. 
Jenkinson C, Coulter A, Bruster S. The Picker Patient Experience Questionnaire: development and validation using data from in-patient surveys in five countries. International Journal for Quality in Health Care, 2002, 14:353-358.

Johns, Merida, ed. Health Information Management Technology: An Applied Approach. Chicago: AHIMA, 2002.

Klazinga N. Re-engineering trust: adoption and adaptation of four external quality assurance models in western European health care systems. International journal for quality in health care, 2000, 12:183-189.

Klazinga NK, Lombarts K, van Everdingen J. Quality management in the medical specialties: the use of channels and dikes in improving health care in the Netherlands. International quality review (Quality review bulletin), 1998, May:240-250.

LawthersA et al. Using outpatient surveys to measure the quality of outpatient care in Krakow, Poland. International journal for quality in health care, 1999, 11:497-506.

Liberati A et al. A European project assessing the appropriateness of hospital utilization: background, objectives and preliminary results. International Journal for Quality in Health Care, 1995, 7:187-199.

McKee M, Healy J. Investing in hospitals. In: McKee M, Healy J, (eds.). Hospitals in a Changing Europe. Buckingham: Open University Press, 2002.

McKee M, Sheldon T. Measuring performance in the NHS. British Medical Journal, 1998, 316:322.

MoumtzoglouA et al. Development and application of a questionnaire for assessing parent satisfaction with care. International journal for quality in health care, 2000, 12:331337.

National Board of Health.National strategy for quality improvement in health care. Copenhagen, 2002, (http://www.sst.dk).

National Health Service patients'survey (http://www.doh.gov.uk).

National recommendations on quality management in health care, 1998 (http://www.aezq.de/gmk3010.pdf).

Onyebuchi A, Arah TC, Klazinga NS. Updating the Key Dimensions of Hospital Performance: The Move Towards a Theoretical Framework. Third Workshop on Hospital Performance Measurement, Barcelona 13-14 June 2003.

Øvretveit J. Quality Evaluation and Indicator Comparison in Health Care.International journal of health planning and management, 2001, 16,3:229-241.

Piskorz K. Impact of accreditation on nursing care. Proceedings of the Polish National Committee on Quality Assurance Conference, Olsztyn, 2002:83-89.

President's Advisory Commission on Consumer Protection and Quality in the Health Care Industry. Quality First: Better Health Care for all Americans. 1998, (http://www.hcqualitycommission.gov/final/). 
Report of the National Expert Advisory Group on Safety and Quality in Australian Health Care.1998 (http://www.health.gov.au/about/cmo/report.doc).

Saloman L et al. Construction of a scale measuring inpatients' opinion on quality of care. International journal for quality in health care, 1999, 11:507-516.

Schneider E, Epstein A. Influence of cardiac-surgery performance reports on referral practice and access to care. New England Journal of Medicine, 1996, 335:251-256.

Scottish Office. Acute Services Review (Carter Report) Edinburgh: Scottish Office Publications, 1998. (http://www.scotland.gov.uk/library/documents5/acute).

Scrivens E. Accreditation: protecting the professional or the consumer? Oxford University Press, 1995.

Secretary of State for Health. The NHS Plan: a plan for investment, a plan for reform. London, Stationery Office, 2000.

Shaw C. External assessment of health care.BMJ 2001, 322:851-854.

Shaw CD, Kalo I. Background to national quality policy in health systems. Copenhagen: World Health Organization, 2002.

Shaw CD. External quality mechanisms for health care: summary of the ExPeRT project on visitation, accreditation, EFQM and ISO assessment in European Union countries. International journal for quality in health care.2000, 12:169-175.

Sierpinska L, Ksykiewicz-Dorota A. Influence of accreditation on the teamwork of medical staff as a direction for improving patient care. Proceedings of the Polish National Committee on Quality Assurance Conference, Lublin, 2002:90-95.

Sitzia J. How valid and reliable are patient satisfaction data? An analysis of 195 studies. International journal of quality in health care, 1999, 11:319-328.

Skurka, Margaret. Health Information Management: Principles and Organization for Health Information Services. San Francisco, CA: Jossey- Bass, 2003.

Steele DR. Promoting Public Confidence in the NHS: The role of the Clinical Standards Board for Scotland. Health bulletin. January 2000. (http://www.scotland.gov.uk/library2/doc09/hbj0-05.asp ).

Sweeney J, Heaton C. Interpretations and variations of ISO 9000 in acute health care. International journal for quality in health care, 2000, 12:203-209.

The International Federation of Health Information Management Associations (2012).

Thompson R, McElroy H, Kazandjian V. Maryland hospital quality indicator project in the UK. Quality in Health Care, 1997, 6:49-55.

Thomson, R. Clinical indicators: do we know what we are doing? Quality in Health Care, 1998, 7:122.

Williamson V et al. Evaluation of the Health Services Accreditation Scheme. Brighton: University of Brighton Health and Social Policy Research Centre, 1998. 
World Health Organization (1994).International Classification of Diseases and Related Health Problems, 10th Revision, Volumes 1, 2 \&3. Geneva: WHO.

World Health Organization Hospital Advisory Group. A review of the determinants of hospital performance. Geneva, 1994.

World Health Organization Regional Office for Europe.Measuring hospital performance to improve the quality of care in Europe: A need for clarifying concepts and defining the main dimensions. Report on a WHO Workshop in Barcelona, Spain, 10-11 January 2003. Copenhagen, World Health Organization, 2003.

World Health Organization, The World Health Report 2000, Health Systems: improving performance, Geneva, 2000. 